\title{
Initial Experience with Single Incision Laparoscopic Appendectomy by Surgical Resident
}

\author{
Jin Hyuk Choi, M.D., Young II Choi, M.D., Ph.D. \\ Department of surgery, Kosin University Gospel Hospital, Kosin University College of Medicine, Busan, Korea
}

Purpose: Laparoscopic appendectomy (LA) is a popular procedure for acute appendicitis. Its minimally invasive nature has made LA a commonly performed surgical technique for surgical residents. However, single incision laparoscopic surgery (SILS) poses a challenge to inexperienced surgical residents. We described our initial experience in teaching SILS for appendectomy in our medical center.

Methods: Twenty nine cases of SILA were performed by single surgical resident and 110 cases of LA were performed by four surgical residents and five board-certified surgeons. Data were reviewed retrospectively.

Results: The mean SILA and multi-port laparoscopic appendectomy (MLA) operative time was $44.5 \pm 14 \mathrm{~min}$ (range 25 85 $\mathrm{min}$ ) and 74.8 $\pm 26 \mathrm{~min}$ (range 20 125 min), respectively. The shorter time for SILA was significant $(p<0.05)$. Postoperative hospital stay was $3.3 \pm 1.6$ days (range $2 \sim 6$ days) following SILA and 4.0 \pm 2.9 days (range $2 \sim 12$ days) following MLA $(p<0.05)$. Three cases of wound infection developed following SILA. Complications in the MLA patients included one cases each of operative bladder injury and postoperative ileus.

Conclusion: SILA is a considerable training method for laparoscopic surgery for a surgical resident learning SILS.

Keywords: Laparoscopic appendectomy, Single incision laparoscopic surgery, Surgical resident
Received October 18, 2017

Revised 1st December 18, 2017 2nd February 17, 2018

Accepted March 16, 2018

Corresponding author

Young Il Choi

Department of Surgery, Kosin University College of Medicine, 34 Amnam-dong, Seo-gu, Busan 49267, Korea

Tel: $+82-51-990-6462$

Fax: +82-51-246-6093

E-mail: tsojc@naver.com

ORCID:

http://orcid.org/0000-0002-9630-6287

This is an Open Access article distributed under the terms of the Creative Commons Attribution Non-Commercial License (http:// creativecommons.org/licenses/by-nc/4.0/) which permits unrestricted non-commercial use, distribution, and reproduction in any medium, provided the original work is properly cited.

Copyright $\odot 2018$ The Journal of Minimally Invasive Surgery. All rights reserved.

\section{INTRODUCTION}

Laparoscopic surgery is the preferred approach for many abdominal procedures. The reported advantages of laparoscopic surgery compared to open surgery are less postoperative pain, fewer wound infections, less hospitalization, and better cosmetic results. ${ }^{1}$ Single incision laparoscopic surgery (SILS) has recently emerged as an alternative to conventional multi-port laparoscopic surgery because of its minimal invasiveness. $^{2}$

Appendectomy is one of the most frequent surgeries per- formed by surgical residents. Single incision laparoscopic appendectomy (SILA) and conventional multi-port laparoscopic appendectomy (MLA) have become the methods of choice for appendectomy by surgical residents.

Several studies have considered the feasibility of MLA for treatment of acute appendicitis by novice surgeons. MLA has also been advocated as a good model for surgical training. ${ }^{3-5}$ Whether SILA is suitable for surgical training is unclear.

The purpose of this study was to determine whether SILA is a suitable method for the single incision laparoscopic training for surgical residents. 


\section{MATERIAL AND METHODS}

After obtaining our institution's ethics committee approval, the study was conducted in Kosin University Hospital, Department of General Surgery. All consecutive laparoscopic appendectomies performed from August 2014 to March 2015 by 4 surgical residents ( 2 third-year residents and 2 secondyear residents) and 5 board-certified surgeons were included in this study. The residents who performed SILA was a thirdyear residents with experience of over 100 cases of MLA. Data were collected retrospectively from medical records. Patient demographics, clinical diagnosis, operative details, and complications were recorded in a clinical database. Outcome variables of interest include body mass index (BMI), American Society of Anesthesiologists (ASA) score, skin-to-skin operative time, length of hospital stay, complications, and additional port insertion. Laparoscopic appendectomy was offered to all patients with the clinical diagnosis of acute appendicitis. There was no specific indication for choosing SILA or MLA. All SILA procedures performed by the same third-year surgical resident were supervised by attending board-certified surgeons. All patients had received a computed tomography (CT) scan in the emergency room. Appendicitis severity ranged from simple to complicated. The decision to insert an additional port was made intraoperatively by the surgical resident. Intravenous antibiotics (stat doses of $2 \mathrm{~g}$ cefotetan) were administered at diagnosis of acute appendicitis in the emergency room.

\section{Surgical procedures}

\section{SILA}

SILA was performed under general anesthesia. The patient lay on the operating table in the supine position with both arms lying outside. The surgeon stood on the left side while the intern scopist was stationed near the foot of the table. After a 2-cm mid-line linear incision was made just above the umbilicus, the abdominal wall was opened using the Hasson technique. Once proper umbilical access was obtained, a Glove Port (Nelis, Seoul, Korea) was positioned and secured within the incision, providing both $360^{\circ}$ wound protection and circumferential atraumatic retraction (Fig. 1). Pneumoperitoneum with carbon dioxide was achieved to a pressure of 10 12 mmHg. SILA was conducted using a $10-\mathrm{mm}$ rigid laparoscope. The appendix was grasped and pulled with a $5-\mathrm{mm}$ rigid grasper immediately on its tip, if visible, or starting from its base or proximal third and gradually mobilizing the entire body of the appendix. The mesentery was carefully dissected and coagulated using LigaSure ${ }^{\mathrm{TM}}$ (Covidien, Mansfield, MA, USA). Once the appendix was fully mobilized and its base on the cecum was identified, the appendix base was knotted twice using a 2-0 Polysorb ${ }^{\mathrm{TM}}$ pre-tied ligating loop (SurgiTie $^{\mathrm{TM}}$; Covidien). After cutting the appendix base with LigaSure ${ }^{\mathrm{TM}}$, the specimen was retrieved under direct vision and extracted through the umbilical Glove Port. The operation was terminated with aspiration and eventual cautious lavage, especially in the right iliac fossa and Douglas pouch, checking hemostasis on the mesentery, and good closure of the appendiceal stump. The umbilical fascia was closed with 2-0 vicryl (Fig. 2).

\section{MLA}

The surgeon and the assistant stood on the left side of the patient. A $10-\mathrm{mm}$ umbilical camera port was inserted using the open Hasson technique. Two 5-mm working ports were inserted under direct vision in the left iliac fossa and the suprapubic region. Appendix and mosoappendix dissections were performed in the same manner as SILA. The appendix was divided after securing the base with 2-0 Polysorb ${ }^{\mathrm{TM}}$ pre-tied ligating loop and subsequently retrieved through the umbilical port in a pouch (Fig. 3).

\section{Statistical analyses}

Student's t-test, $\chi^{2}$ test, Fisher's exact probability test, and the Mann-Whitney U test were used for analyses of parametric and non-parametric data, as appropriate. Statistical analyses were performed using SPSS ver. 22.0 (IBM, New York, NY, USA). Differences of $p<0.05$ were considered significant.

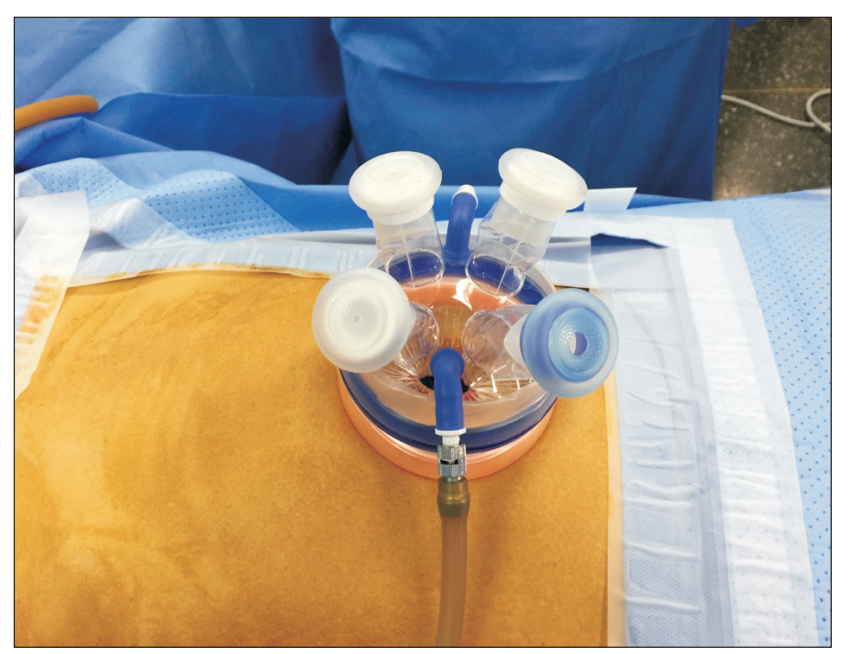

Fig. 1. Glove port used for single incision laparoscopic appendectomy. 


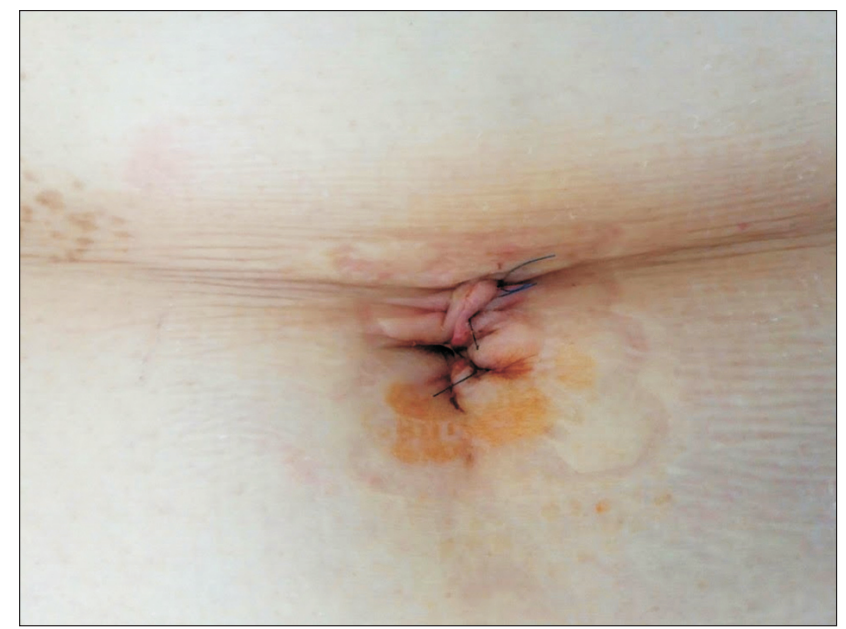

Fig. 2. Postoperative scars in single incision laparoscopic appendectomy.

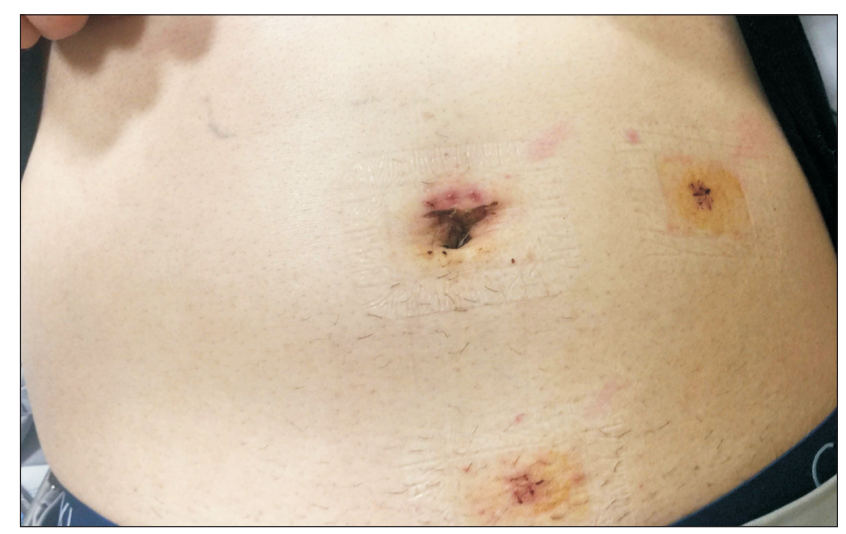

Fig. 3. Postoperative scar in multi-port laparoscopic appendectomy.

\section{RESULTS}

\section{Demographics characteristics of patients}

During the 8-month study period, 154 patients underwent laparoscopic appendectomy. Fifteen patients with comorbid conditions that included congestive heart failure, liver cirrhosis, dementia, and pregnancy, which could affect the surgical outcome, were excluded leaving 139 cases for analysis. Mean age, BMI, and ASA scores of the SILA group were significantly lower than those of the MLA group. Sex and the severity of appendicitis were comparable (Table 1).

\section{Perioperative outcomes}

Table 2 shows the perioperative data. The mean operative time in SILA and MLA groups was 44.5 \pm 14 min (range 25 85 min) and $74.8 \pm 26$ min (range 20 125 min), respectively. The
Table 1. Patient characteristics

\begin{tabular}{lccc}
\hline & $\begin{array}{c}\text { SILA group } \\
(\mathbf{n}=29)\end{array}$ & $\begin{array}{c}\text { MLA group } \\
(\mathbf{n}=110)\end{array}$ & $p$ value \\
\hline Age, years & 26.7 & 39.4 & 0.02 \\
Men $(\%)$ & $12(41.4)$ & $62(56.4)$ & NS \\
Body mass index $\left(\mathrm{kg} / \mathrm{m}^{2}\right)$ & 20.8 & 23.2 & 0.03 \\
ASA-PS $\geq 3(\%)$ & $1(4)$ & $3(3)$ & NS \\
Complicated appendicitis $(\mathrm{n})$ & 2 & 10 & NS \\
\hline
\end{tabular}

SILA = single incision laparoscopic appendectomy; MLA = multi-port laparoscopic appendectomy; ASA-PS = American Society of Anesthesiologists physical status; NS $=$ not significant.

Table 2. Comparison of intraoperative and postoperative outcomes between the SILA and MLA groups

\begin{tabular}{lcccc}
\hline & $\begin{array}{c}\text { SILA group } \\
\text { (n=29) }\end{array}$ & $\begin{array}{c}\text { MLA group } \\
(\mathbf{n}=110)\end{array}$ & p value \\
\hline Operating time (min) & 44.5 & 74.8 & 0.01 \\
Additional port insertion (n) & 3 & 0 & 0.01 \\
Postoperative hospital stay (days) & 3.3 & 4.0 & 0.04 \\
Postoperative complications (n) & 3 & 2 & NS
\end{tabular}

SILA = single incision laparoscopic appendectomy; MLA = multi-port laparoscopic appendectomy; NS = not significant.

time was significantly shorter in the SILA group $(p<0.05)$. Postoperative hospital stay was $3.3 \pm 1.6$ days (range $2 \sim 6$ days) following SILA and 4.0 \pm 2.9 days (range 2 12 days) following MLA $(p<0.05)$. Three of the 29 cases in the SILA group were converted to multi-port (two-port) surgery $(p<0.05)$. Perioperative complications were evident in 3 patients in the SILA group and 2 of the 110 patients in the MLA group. Complications included 3 cases of wound infection in the SILA group and 1 case each of postoperative ileus and bladder injury during port insertion in the MLA group.

In the 110 MLA surgeries, 50 were performed by the 4 surgical residents. Table 3 shows the perioperative data between SILA performed by one surgical resident and MLA by the four surgical residents. The mean operative time in the SILA and MLA groups was $44.5 \pm 14$ min and $56.4 \pm 20$ min (range 20 115 min), respectively. The surgery was significantly shorter in the SILA group $(p<0.05)$. The mean postoperative hospital stay was $3.3 \pm 1.6$ days following SILA and 3.8 \pm 1.6 days (range $2 \sim 9$ days) following MLA $(p=0.2)$. 
Table 3. Comparison of intraoperative and postoperative outcomes between the SILA and MLA groups ISILA group vs MLA group by the surgical residents)

\begin{tabular}{lccc}
\hline & $\begin{array}{c}\text { SILA group } \\
(\mathrm{n}=\mathbf{2 9})\end{array}$ & $\begin{array}{c}\text { MLA group } \\
(\mathrm{n}=\mathbf{5 0})\end{array}$ & $p$ value \\
\hline Operating time (min) & 44.5 & 56.4 & 0.01 \\
Additional port insertion (n) & 3 & 0 & 0.02 \\
Postoperative hospital stay (days) & 3.3 & 3.8 & NS \\
Postoperative complications $(\mathrm{n})$ & 2 & 2 & $\mathrm{NS}$ \\
\hline
\end{tabular}

SILA = single incision laparoscopic appendectomy; $M L A=$ multi-port laparoscopic appendectomy; NS = not significant.

\section{DISCUSSION}

The concept of surgical training has changed. Minimal invasive surgery is considered the standard for a wide range of surgical procedures. SILS is an intermediate stage of conventional multiport surgery and natural orifice transluminal endoscopic surgery. ${ }^{6}$ The use of single-incision procedures has markedly increased, reflecting their ability to be performed with conventional laparoscopic instrumentation. In urology, SILS results in scarless surgery with reduced wound morbidity. ${ }^{7.8}$ The safety and feasibility of SILS for both benign and malignant colorectal disease has been proven. ${ }^{9}$ Recently, liver resection has been attempted with SILS. ${ }^{10-12}$ Although the use of SILS is becoming widespread, technical difficulty has delayed its adoption for surgical cases.

Appendectomy is the first surgery to be done in the training of surgical residents. It is very important to learn open appendectomy and laparoscopic appendectomy in the course of training. Appendectomy is one of the most common acute abdominal conditions experienced by a surgical resident, and careful observation and physical examination are required when diagnosed. Surgery is relatively easy because of the thin mesentery and fewer blood vessels. So, it can be the basic basis of learning upper surgeries. ${ }^{13}$ Laparoscopic cholecystectomy is a typical laparoscopy procedure. It is established as a primary operation for asymptomatic gallstone disease and gallbladder polyposis. Single incision laparoscopic cholecystectomy is also not technically difficult. However, complications that include damage of the common bile duct when ligation of the bile duct and gallbladder arteries by dissected the Calot triangle may be a source of trepidation for beginners. ${ }^{14}$ Despite this, laparoscopic appendectomy is a relatively safe and effective procedure, and is considered as a suitable procedure for surgeons to begin their training with SILS.

We have previously reported that MLA was safe and suit- able for surgeons who initially learned laparoscopic surgery at our center. ${ }^{4}$ We wanted to make sure that SILA is a suitable surgery for the surgical resident who is embarking on SILS. In our center, the first- and second-year surgical residents mainly perform the open appendectomy and MLA procedures. Third-year or higher residents commenced SILA training under the supervision of an attending surgeon.

The SILA group was statistically significantly lower than the MLA group in age and BMI. This suggests a bias in the selection of patients in the SILA group. It is likely that the attending surgeon and participating resident selected younger patients with low BMI and simple appendicitis on CT scan when they decided on patients for the single incision laparoscopic procedure.

The operative time and postoperative hospitalization were shorter in the SILS group. Other parameters were not statistically significant. A prior study reported no significant difference in operative time and hospital days between MLA and SILS performed by four experienced surgeons. ${ }^{15}$ However, a meta-analysis of 6 published studies reported that the operative time was longer in the SILS group, with no significant difference in hospital stay. ${ }^{3}$ In another study, patients were randomized into three groups: open appendectomy (OA), MLA, and SILA. The mean operative time in the SILA group was significantly longer than the open OA group, and the length of hospital stay in the SILA and MLA groups was significantly lower than the OA group. ${ }^{16}$ There were no differences between the two groups in the other surgical outcomes, including the frequency of complications, except for differences in hospitalization period and operation time. Still another study compared the outcomes of SILA performed by residents and attending groups; the estimated amount of bleeding was significantly higher in the resident group and the operating time tended to be longer in the resident groups. ${ }^{17}$ The present results vary somewhat from these prior studies, which may reflect the low BMI and simple appendicitis features of the SILA group. Furthermore, the resident who performed SILA was a third-year resident with experience of over 100 cases of MLA.

Limitations of the study include the retrospective review design and small number of patients. A study with a larger cohort across multiple centers by many surgeons should be performed to accurately determine the feasibility of SILA as a training tool.

\section{CONCLUSION}

This study demonstrates SILA to be considered as a method of training in laparoscopic surgery for residents with sufficient MLA experience if patients are appropriately selected. SILA is a safe and practicable procedure for surgical residents and the 
outcomes are acceptable and provide superior cosmetic results.

\section{ACKNOWLEGMENTS}

This study was carried out by the research fund of Kosin University School of Medicine.

\section{REFERENCES}

1) Biondi A, Di Stefano C, Ferrara F, Bellia A, Vacante M, Piazza L. Laparoscopic versus open appendectomy: a retrospective cohort study assessing outcomes and cost-effectiveness. World J Emerg Surg 2016;11:44.

2) Deveci U, Barbaros U, Kapakli MS, et al. The comparison of single incision laparoscopic cholecystectomy and three port laparoscopic cholecystectomy: prospective randomized study. J Korean Surg Soc 2013;85:275-282.

3) Cai YL, Xiong XZ, Wu SJ, et al. Single-incision laparoscopic appendectomy vs conventional laparoscopic appendectomy: systematic review and meta-analysis. World J Gastroenterol 2013;19:5165-5173.

4) Seo K, Choi Y, Choi J, Yoon K. Laparoscopic Appendectomy is Feasible for Inexperienced Surgeons in the Early Days of Individual Laparoscopic Training Courses. J Korean Surg Soc 2009;76:2327.

5) Lin YY, Shabbir A, So JB. Laparoscopic appendectomy by residents: evaluating outcomes and learning curve. Surg Endosc 2010;24:125-130.

6) Antoniou SA, Antoniou GA, Antoniou AI, Granderath FA. Past, Present, and Future of Minimally Invasive Abdominal Surgery. Jsls 2015;19.

7) Sherif H, El-Tabey M, Abo-Taleb A, Abdelbaky A. Single- incision laparoscopic surgery in urology. Curr Urol 2012;6:8-14.

8) Kaouk JH, Haber GP, Goel RK, et al. Single-port laparoscopic surgery in urology: initial experience. Urology 2008;71:3-6.

9) Keller DS, Haas EM. Single-Incision Laparoscopic Colon and Rectal Surgery. Clin Colon Rectal Surg 2015;28:135-139.

10) Chang SK, Mayasari M, Ganpathi IS, Wen VL, Madhavan K. Single port laparoscopic liver resection for hepatocellular carcinoma: a preliminary report. Int J Hepatol 2011;2011:579203.

11) Ban D, Kudo A, Irie T, et al. Advances in reduced port laparoscopic liver resection. Asian J Endosc Surg 2015;8:11-15.

12) Aikawa M, Miyazawa M, Okamoto K, et al. Single-port laparoscopic hepatectomy: technique, safety, and feasibility in a clinical case series. Surg Endosc 2012;26:1696-1701.

13) Graat LJ, Bosma E, Roukema JA, Heisterkamp J. Appendectomy by residents is safe and not associated with a higher incidence of complications: a retrospective cohort study. Ann Surg 2012;255:715-719.

14) Koo EJ, Youn SH, Baek YH, et al. Review of 100 cases of single port laparoscopic cholecystectomy. J Korean Surg Soc 2012;82:179-184.

15) Raakow J, Liesaus HG, Neuhaus P, Raakow R. Single-incision versus multiport laparoscopic appendectomy: a case-matched comparative analysis. Surg Endosc 2015;29:1530-1536.

16) Sozutek A, Colak T, Dirlik M, Ocal K, Turkmenoglu O, Dag A. A prospective randomized comparison of single-port laparoscopic procedure with open and standard 3-port laparoscopic procedures in the treatment of acute appendicitis. Surg Laparosc Endosc Percutan Tech 2013;23:74-78.

17) Endo K, Kujirai D, Maeda $H$, et al. Transumbilical laparoscopic appendectomy performed by residents is safe and feasible. Asian J Endosc Surg 2016;9:270-274. 